\title{
The Influence of Environmental Factors on College Students' Online Catering Ordering
}

\author{
Jia Chen ${ }^{\mathrm{a}}$ \\ School of Health Management \& Rehabilitation, Zhongshan Vocational College, 210049, Nanjing, China
}

\begin{abstract}
The catering $\mathrm{O} 2 \mathrm{O}$ platform has greatly enriched people's catering options, saving the cost of catering enterprises and consumers, and thus has achieved great development in recent years. The data provided by the $\mathrm{O} 2 \mathrm{O}$ platform provides a good condition for us to study the impact of natural environmental factors on food and beverage consumption. With the help of 'Eleme' app, we collected the online catering data of about 30 restaurants around Zhongshan Vocational College, and established a multiple regression model for the online catering sales, then we used this model to study the impact of weather, wind, temperature, air pollution, and weekend/holiday on online catering orders. Our results showed that the online catering orders increased gradually with increase of the rainfall and the temperature. This is probably because the rainfall and high temperature increase the cost of people going out to eat, and thus increase the possibility of online ordering; air pollution and the increase in wind power did not significantly affect the online catering orders, which may be due to the fact that these two factors did not reach the level of serious impact on people's activities during the study period. The weekend/holiday effect was very significant in this study, and people significantly increased the online ordering on weekends or holidays, probably because people were having rest. For the first time, our research uses $\mathrm{O} 2 \mathrm{O}$ platform data to quantitatively study the impact of natural environmental factors on online catering sales, and our research provides an important management reference for online catering enterprises
\end{abstract}

\section{INTRODUCTION}

Catering $\mathrm{O} 2 \mathrm{O}$ mode means that consumers can order the food of the physical food and beverage store online through the computer or mobile phone app. After the meal service is finished, the customer can also score and comment on the business according to the online consumption experience [1]. Since 2012, the Eleme, Meituan, Baidu take-out and other take-out platforms have been launched, and consumer orders have gradually turned to mobile phones [2]. Compared with the traditional telephone-based take-out order mode, the catering $\mathrm{O} 2 \mathrm{O}$ reduces the information search cost of the consumer to obtain the take-out business information and the menu of the meal, increases the ordering area, increases the selection and evaluation reference of the catering variety, and for the take-away merchant In terms of catering $\mathrm{O} 2 \mathrm{O}$, merchants have gained more promotion opportunities, saving manpower and increasing the number of take-away sales[2].

Basically, catering $\mathrm{O} 2 \mathrm{O}$, that is, online ordering, is also a consumer behavior, which, besides being demanded by consumers themselves, is also stimulated and influenced by many environmental factors[3, 4]. These stimuli affect consumers' perceptions, emotions, and moods, which in turn affect consumer behavior [4].

Weather factors may be one of the important factors affecting consumer behavior [5-7]. For consumers, rainy weather means inconvenient travel, going out will increase more time costs and even security costs, so consumers' desire to go out to consume has been suppressed, and the tendency of online consumption has been strengthened[7, 8]. From this perspective, we can expect that as the rainfall level increases, the sales of online ordering will gradually increase.

Air pollution conditions may also affect online ordering. Air pollution, especially the pollution of PM2.5, has been affecting all aspects of people's lives. Numerous studies have shown that smog pollution not only affects people's health, increases the risk of cardiovascular and cerebrovascular diseases, cancer, etc. $[9,10]$, but also significantly affects people's behavior $[11,12]$. When air pollution is severe, people are more willing to stay indoors and reduce the time of outdoor activities [11]. Therefore, we can also expect that as air pollution intensifies, online catering sales will continue to increase.

Weekend or holiday effects are also evident in consumer behavior $[13,14]$. On weekends or holidays, people have more and free time for comparison and choice, consumer desires will be released, and consumer behavior will be significantly improved. On weekdays, limited by learning or work, consumer behavior will be more suppressed of various factors [14]. The main target for online ordering around universities is the students. From Monday to Friday, the students usually have

\footnotetext{
${ }^{\text {a }}$ Corresponding author: 26500068@qq.com
} 
regular classes, thus should choose more in the school restaurant. While at weekends or holidays, time is often flexible for students. A wide variety of take-outs, can improve food diversity, and there should be higher sales.

Based on the above research background, we conducted research on the factors affecting online order sales in the first half of 2016. By collecting online takeout sales orders and establishing a multiple regression model, we quantitatively analyzed the impact of weather, air quality and working days on college students' takeout orders. It is hoped that through this research, it can provide a useful reference for the sales and management of online catering enterprises.

\section{METHODS}

\subsection{Data source and variable definition}

The $\mathrm{O} 2 \mathrm{O}$ online fast food sales platform in Nanjing is mainly hungry and the US group. Considering that it is hungry in 2016, it is more widely used in the students of Zhongshan Vocational and Technical College. Therefore, this study is based on the hungry platform. Online sales data of about 30 fast food restaurants near Zhongshan Vocational College were collected. The collection time started from March 22, 2016 and ended on June 22, 2016, for a total of 93 days.

The weather and air pollution data are collected from the weather post website (tianqihoubao.com) and the data center of the Ministry of Ecology and Environment (datacenter.mep.gov.cn). The weather data mainly collects the temperature, wind, rainfall and air pollution data of the day. The air quality index (AQI) was collected. For rainfall data, we divide the weather into four levels according to the presence or absence of rainfall and rainfall: no rain (including sunny, cloudy, overcast), light rain or showers, moderate rain, heavy rain or heavy rain. We did not record the humidity data because the humidity data is positively correlated with the rainy data, and the rainy data is kept more concise and intuitive. For wind data, we are divided into three levels according to the level: less than or equal to level 3 , level 3-4, and greater than level 4. The temperature is the highest temperature of the day and is defined as a continuous variable.

According to the definition of AQI (GB3095-2012) by the Ministry of Ecology and Environment, its values are taken from fine particulate matter (PM2.5), inhalable particulate matter (PM10), sulfur dioxide (SO2), nitrogen dioxide (NO2), carbon monoxide $(\mathrm{CO})$, The highest value of the six pollutants such as ozone (O3). AQI values range from 0 to 500 , and can be classified into six categories (Good: 0-50, Moderate: 51-100, Unhealthy for Sensitive Groups: 101-150, Unhealthy: 151-200, Very Unhealthy: 200-300, Hazardous: 301$500)$. Considering that there was only one day air was severely polluted during the study period (May 7), and the rest were excellent or slightly polluted, we divided the AQI into three levels according to the pollution level: excellent, good, and polluted.
For the definition of dates, we briefly distinguish between workdays and rest days. During the study period, there were no consecutive holidays of more than three days. There were only three short holiday days on April 4, Qingming Festival, May 1 Labor Day and June 9 Dragon Boat Festival, so we will have these three statutory holidays. And weekends are defined as rest days, and others are defined as working days. During the study period, there were 64 working days and 29 rest days.

\subsection{Model construction and data analysis}

In examining the relationship between take-away sales and weather variables and holiday variables, this study used a multivariate regression model analysis method. Using the generalized linear model, this paper builds the following model:

Order $=\beta 0+\beta 1 *$ Weather $+\beta 2 *$ Wind $+\beta 3 *$ Temperature + $\beta 4 * \mathrm{AQI}+\beta 5^{*}$ Holiday

Among them, Order is the total amount of orders, and $\beta$ is the coefficient of each factor of the model. Except that $\beta 0$ is the constant, the others are the coefficients of the corresponding independent variables. Weather variable includes four levels of no rain, light rain, moderate rain, heavy rain rain; Wind variable contains three levels of less than 3, 3-4, and greater than 4; Temperature is defined as a continuous variable; AQI is the air quality index, which includes three levels of excellent, good, and polluted; Holiday is a weekend or holiday variable, including two levels of working day and rest day. The model construction and analysis process were all performed on SPSS18.0. The data in the text is expressed as mean \pm standard error, and the significance is defined as 0.05 .

\section{RESULTS}

In the first half of 2016, there were about 30 fast food restaurants around Zhongshan Vocational College. The daily average delivery was $736.3 \pm 7.4$, including Chinese food delivery $633.9 \pm 5.7$, and Western food delivery $102.0 \pm 1.9$. During this period, the highest temperature in Nanjing reached $33{ }^{\circ} \mathrm{C}$, the lowest was $12{ }^{\circ} \mathrm{C}$, the average was $23.6 \pm 0.5^{\circ} \mathrm{C}$; the air quality index AQI reached 287 , the lowest was 36 , and the average was $76.7 \pm 3.2$. The days of AQI for excellent, good, and polluted were 13 days, 70 days, and 10 days, respectively.

The order is a dependent variable, and the environmental factors including weather, wind, temperature, AQI, and the date factor of the working state are input into the generalized linear model, and a multiple regression model of online take-out sales is established. The model R2 reaches 0.37 , which means that $37 \%$ of the take-away sales changes can be explained by using the above factors. The results showed that rainy $(\mathrm{F} 3,83=7.321, \mathrm{P}<0.001)$, temperature $(\mathrm{F} 1$, $83=6.316, \quad \mathrm{P}=0.014)$ and rest days $(\mathrm{F} 1,83=15.272$, $\mathrm{P}<0.001)$ all significantly affected the sales of online takeaway. The wind $(\mathrm{F} 2,83=1.156, \mathrm{P}=0.320)$ and 
AQI $(F 2,83=1.156, P=0.320)$ did not produce significant effects (Table 1, Table 2).

Table 1 Multiple regression model of effects of environmental factors and weekends on the online orders of takeaways

\begin{tabular}{cccc}
\hline Factors & Freedom df & $\mathrm{F}$ & $\mathrm{P}$ \\
\hline intercept & 1 & 409.954 & 0.000 \\
Weather & 3 & 7.321 & 0.000 \\
Wind & 2 & 1.156 & 0.320 \\
Temperature & 1 & 6.316 & 0.014 \\
AQI & 2 & 0.984 & 0.378 \\
Working day & 1 & 15.272 & 0.000 \\
Error & 83 & & \\
In total & 93 & & \\
\hline
\end{tabular}

Table 2 Parameter estimates of multiple regression model of the online orders of takeaways

\begin{tabular}{ccccc}
\hline Parameter & B & S.E. & T & P \\
\hline Intercept & 780.801 & 51.809 & 15.071 & 0.000 \\
No rain & -74.296 & 38.847 & -1.913 & 0.059 \\
light rain & -14.962 & 40.374 & -0.371 & 0.712 \\
moderate rain & 7.454 & 37.641 & 0.198 & 0.844 \\
Heavy rain & $0 \mathrm{a}$ & - & - & - \\
Wind $\leq 3$ & -7.811 & 24.689 & -0.316 & 0.752 \\
Wind 3-4 & -25.032 & 19.099 & -1.311 & 0.194 \\
Wind $>4$ & $0 \mathrm{a}$ & - & - & - \\
Temperature ${ }^{\circ} \mathrm{C}$ & 3.623 & 1.442 & 2.513 & 0.014 \\
AQI-Excellent & -37.519 & 29.510 & -1.271 & 0.207 \\
AQI-Good & -25.645 & 21.330 & -1.202 & 0.233 \\
AQI-Polluted & $0 \mathrm{a}$ & - & - & - \\
Working days & -53.364 & 13.655 & -3.908 & 0.000 \\
Rest days & $0 \mathrm{a}$ & - & - & - \\
\hline
\end{tabular}

Note, a, basic level.

The impact of sales on the rainy days is very obvious. It is estimated from the model parameters that the sales volume has increased significantly as the weather changes from sunny to light rain and moderate rain, and when the weather is bad to heavy rain or heavy rain, the sales volume is slightly reduced. 1). When controlling other variables, it can be found that, compared with the rain-free weather $(733.3 \pm 12.1$ parts/day), the take-out increased by $8.1 \%$ in the case of light rain $(792.6 \pm 17.5$ parts/day), and in the rainy weather $(815.1 \pm 20.2$ parts/day) Increase by $11.2 \%$, and increase by $10.1 \%$ in heavy rain or heavy rain $(807.6 \pm 34.7$ copies/day). Temperature also significantly affects the sales of takeouts. It can be estimated from the model estimate that for every $1{ }^{\circ} \mathrm{C}$ increase in temperature, the sales volume increases by $3.6 \pm 1.4$, which is an increase of about $0.5 \%$.

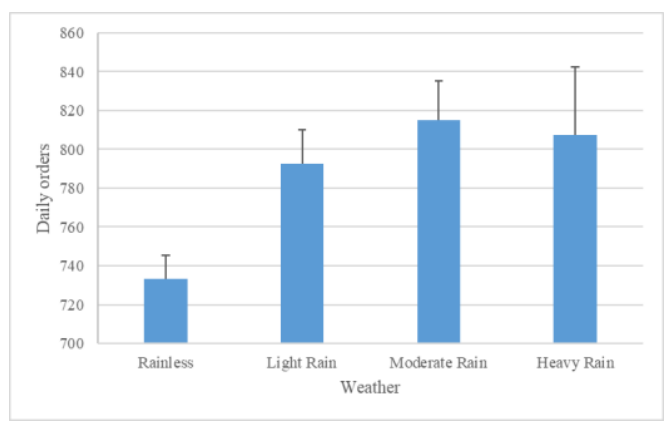

Figure 1 Impact of weather conditions on the online orders of takeaways

There is no obvious impact of wind on the sales (Figure 2). Air quality levels have no significant impact on sales, but from a trend perspective, air pollution does increase sales (Figure 3). Considering that this study is a spring and summer season, the air quality is good, and there is almost no moderately polluted weather. This result is also understandable.

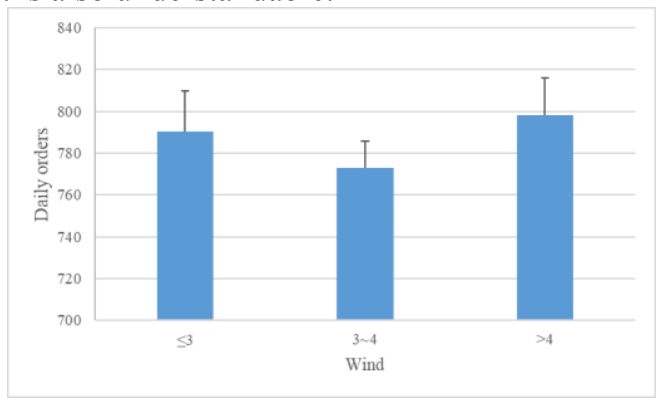

Figure 2 Impact of wind power on the online orders of takeaways

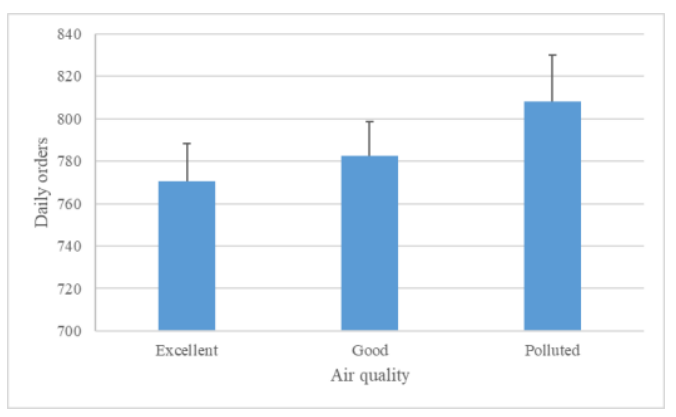

Figure 3 Impact of air quality on the online orders of takeaways

The rest day does increase the sales of takeaways significantly (Figure 4). According to the model estimate, the sales on the rest day $(813.8 \pm 14.7$ copies / day $)$ can be increased by $7 \%$ compared to the working day ( 760.5 \pm 12.3 copies / day). 


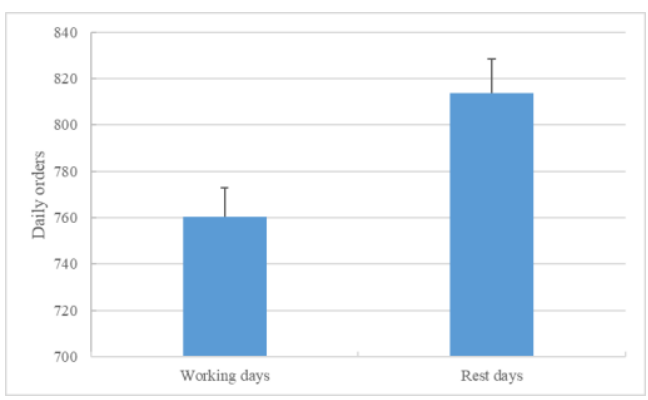

Figure 4 Impact of workday/weekend on the online orders of takeaways

\section{DISCUSSION}

In the past, the research on the environmental impact factors of catering consumption behavior mostly focused on the physical environment, such as restaurant location and decoration $[15,16]$, while the research on the impact of natural environment was relatively rare. The rise of catering $\mathrm{O} 2 \mathrm{O}$ has significantly reduced the impact of the catering physical environment on catering consumption behavior, providing a good opportunity to study the impact of natural environmental factors, including weather and air quality, on catering consumption behavior.

As expected, the rainy weather will increase the sales of online catering. As the rainfall increases, the takeaway orders gradually increase. Rainfall will increase the difficulty of people's travel, increase the time and safety cost people spend on food and beverage consumption. As the rainfall increases, people's willingness to choose to take out food is also strengthened. This is also confirmed by many questionnaires. For example, in an online survey of 154 questionnaires on the Questionnaire website, $70.8 \%$ of people will consider the impact of bad weather on personal catering behavior (https://www.wjx.cn/report/11685895.aspx). In fact, rainy weather will greatly increase people's online consumption behavior, such as rainfall weather will significantly provide eBay website volume, the greater the rainfall, the greater the trade of ebay website [17] . However, it is worth noting that when the rain reaches heavy rain, the online order starts to drop slightly, which is probably because the rainfall greatly increases the transport cost, and the consumer's empathy for the delivery staff will also reduce the online ordering tendency.

In this study, we found that air pollution has a tendency to increase online catering orders, but it has not reached a significant level. A large number of studies have shown that air pollution, especially smog pollution, can greatly affect people's behavior and psychology, such as reducing people's outdoor activities, increasing people's discomfort, causing irritability, depression, etc. $[11,12]$. These behavioral and psychological changes will significantly affect people's consumption behavior. The reason why our research did not find obvious pollution effects is probably because the time of our research coincides with the spring and summer, air pollution is not serious. In future research, increasing the sample of severe autumn and winter smog pollution will help us quantitatively describe the impact of smog pollution on online catering consumption behavior.

The holiday effect has been verified in our research, with online orders on weekends or holidays being 7\% higher than working days. For students in school, Monday to Friday is a concentrated study time, regular work schedule, fixed activities, regular canteen dining to help study arrangements; and Saturday or Sunday or three days of small holidays, students relax And leisure time, the mood is more pleasant and comfortable, the time is more free and ample, online ordering can meet the students' choice of preferred food varieties, increase the time of free enjoyment, which was also verified in a 102 online survey. $57.9 \%$ of people prefer to choose to take out on weekends, while only $18.6 \%$ prefer to choose take-away on weekdays (https://www.wjx.cn/report/12551792.aspx). In fact, weekend or holiday effects of consumer behavior have been validated in many studies [5, 6, 13, 17].

Our research also found that in the spring and summer, as the temperature increases, online orders will gradually increase, which is probably because the high temperature gradually increases the discomfort of outdoor activities, accompanied by the yellow plum in the spring and summer of Nanjing. The weather has caused students to reduce their tendency to go out to eat, and chose to order food online. Wind has no effect on online orders, probably because there was no significant wind during the study period, and students did not have a distinctly different perception of winds below level 5 .

\section{CONCLUSION}

In summary, although the survey area of this study is limited to dozens of takeaway stores in a location around Nanjing Zhongshan Vocational College, compared with the traditional research relying on questionnaires, this is the first quantitative study on the impact of rainfall, temperature, air pollution and holidays on online takeout sales. We found that online orders did increase significantly with increasing rainfall, rising temperatures, and weekends, which resulted in food preparation and meals for online catering companies. This is useful for production, catering, distribution and management of fast food factories. Future research can further expand research time and space, and use big data to perfect this model whenever possible.

\section{Acknowledgement}

This research was supported by the research fund of the Zhongshan Vocational College (2018-2019).

\section{References}

1. S. Wang, China Bussiness Trade 5, 5(2015)

2. T.J. Wu, R.H. Zhao \& S.Y. Tzeng, Journal of Interdisciplinary Mathematics 18, 6(2015) 
3. G.H. Haines, J.A. Howard \& J.N. Sheth, Journal of the American Statistical Association 65, 331(1970)

4. F.J.M. Laros \& J.B. Steenkamp, Journal of Business Research 58, 10(2005)

5. G.G. Lim, D.H. Kim, M. Choi, J.H. Choi \& K.C. Lee, Online Information Review 34, 1(2010)

6. K.B. Murray, A. Finn, P.P. Leszczyc \& F. Di Muro, Advances in Consumer Research, Vol 35 35, 2008)

7. A.G. Parsons, Australasian Marketing Journal 9, 2(2001)

8. S. Saneinejad, M.J. Roorda \& C. Kennedy, Transportation Research Part D-Transport and Environment 17, 2(2012)

9. M. Neuberger, M.G. Schimek, F. Horak, H. Moshammer, M. Kundi, T. Frischer, B. Gomiscek, H. Puxbaum, H. Hauck \& Auphep-Team, Atmospheric Environment 38, 24(2004)

10. D.W. Dockery \& C.A. Pope, Annual Review of Public Health 15, 1994)

11. S.A. Rajper, S. Ullah \& Z.Q. Li, Plos One 13, 3(2018)

12. G.Y. Sui, G.C. Liu, L.Q. Jia, L. Wang \& G.L. Yang, Environmental Science and Pollution Research 25, 28(2018)

13. E.M. Miller, Journal of Portfolio Management 14, 4(1988)

14. Y. Sugie, J. Zhang \& A. Fujiwara, Journal of Retailing and Consumer Services 10, 6(2003)

15. V.C.S. Heung \& T.M. Gu, International Journal of Hospitality Management 31, 4(2012)

16. K. Ryu \& H. Han, Journal of Hospitality \& Tourism Research 34, 3(2010)

17. O. Hinz, S. Hill \& J. Kim, Management Information Systems Quarterly 40, 3(2016) 